\title{
Jurnal Keislaman
}

p-ISSN : 2089-7413 and e-ISSN : 2722-7804

Published by Sekolah Tinggi Agama Islam Taruna Surabaya

Jl. Kalirungkut Mejoyo I No. 2, Kec. Rungkut, Kota Surabaya, Jawa Timur 60293

Email: jurnalkeislaman@staitaruna.ac.id

\section{TEOLOGI HASAN HANAFI DAN RELEVANSINYA DENGAN REVOLUSI INDUSTRI 4.0}

\author{
Muhammad Yuslih \\ Universitas Islam Negeri Sunan Kalijaga Yogyakarta \\ Email : muhammadyuslih48@gmail.com
}

\begin{abstract}
A person's actions or behavior cannot be taken from the beliefs or theological schools he adheres to, because it will become the basic foundation in everyday life. This paper aims to reveal the theological ideas of Hasan Hanafi, who is one of the leading theologians or contemporary kalam, and how it relates to the industrial revolution 4.0. This type of research is included in the category of library research. The data obtained in this study were sourced from the results of reading and searching related to Hasan Hanafi's theological ideas and also the Industrial revolution 4.0 from various books, journals, the internet and other sources. The results of the research and reading of the researcher show that the industrial revolution 4.0 requires humans to take $a$ role and present themselves, besides that the readiness of responsive and innovative human resources is an absolute requirement, and has extensive knowledge in facing the industrial revolution 4.0. In addition, humans must avoid all forms of behavior that damage or harm themselves, and strengthen brotherhood. All of these have relevance to the theological concepts initiated by Hasan Hanafi, namely Wujud (existent), Qhidam (formerly), Mukhalafatu Li Al-Hawadist (Different from Others) and Qiyam Binafsihi (Standing Alone), Baqa' (eternal), Wahdaniyyah (unity).
\end{abstract}

Keywords: Theology, Hasan Hanafi, Industrial Revolution, 4.0

\begin{abstract}
Abstrak
Tindakan atau perilaku seseorang tidak dapat diambil dari keyakinan atau sekolah teologis yang dia patuhi, karena itu akan menjadi dasar dasar dalam kehidupan sehari-hari. Makalah ini bertujuan untuk mengungkapkan gagasan teologis Hasan Hanafi, yang merupakan salah satu teolog terkemuka atau kalam kontemporer, dan bagaimana kaitannya dengan revolusi industri 4.0. Jenis penelitian ini termasuk dalam kategori penelitian perpustakaan. Data yang diperoleh dalam penelitian ini bersumber dari hasil membaca dan mencari terkait gagasan teologis Hasan Hanafi dan juga revolusi Industri 4.0 dari berbagai buku, jurnal, internet dan sumber lainnya. Hasil penelitian dan pembacaan peneliti menunjukkan bahwa revolusi industri 4.0 mengharuskan manusia untuk mengambil peran dan menampilkan diri, selain itu kesiapan sumber daya manusia yang responsif dan inovatif merupakan syarat mutlak, serta memiliki pengetahuan yang luas dalam menghadapi revolusi industri 4.0. Selain itu, manusia harus menghindari segala bentuk perilaku yang merusak atau merugikan diri mereka sendiri, dan memperkuat persaudaraan. Semua ini memiliki relevansi dengan konsep teologis yang diprakarsai oleh Hasan Hanafi, yaitu Wujud (ada), Qhidam (sebelumnya), Mukhalafatu Li Al-Hawadist (Berbeda dari Yang Lain) dan Qiyam Binafsihi (Berdiri Sendiri), Baqa ' (abadi), Wahdaniyyah (persatuan).
\end{abstract}

Kata kunci: Teologi, Hasan Hanafi, Revolusi Industri, 4.0 


\section{TEOLOGI HASAN HANAFI DAN RELEVANSINYA DENGAN REVOLUSI INDUSTRI 4.0 - Muhammad Yuslih}

\section{Pendahuluan}

Teologi dan prilaku memiliki hubungan yang tidak dapat bisa dipisahkan. Karena apa yang diyakini oleh seseorang akan menjadi pijakan dasar dalam melakukan tindakan, seperti halnya aliran Jabariyah (fatalisme) yang meyakini bahwa manusia tidak memiliki kewenangan dalan menentukan takdir, sehingga dalam berprilaku sehari-sehari lebih dominan bertawakkal daripada berusaha, tetapi sebaliknya yang terjadi pada aliran Qodariah yang meyakini bahwa kewenangan takdir ditentukan oleh manusia, sehingga dalam kehidupan sehari hari-hari memberikan porsi yang lebih besar kepada usaha manusia. ${ }^{1}$

Munculnya berbagai aliran teologi dalam Islam tidak lepas dari peristiwa terjadinya perang Shiffin antara pasukan Khalifah 'Ali bin Abi Thalib dengan pasukan Muawiyah bin Abi Sufyan dan menjadi tonggak awal perpecahan umat Islam yang berlarut-larut. Aliran pertama dalam teologi Islam diawali oleh Khawarij yang mendeklarasikan diri keluar dari kelompok Ali karena menganggap Ali telah menyimpang dari hukum Allah swt, kemudian di susul oleh aliran Mu'tazilah. Pada dasarnya lahirnya kedua aliran ini reaksi dari peristiwa perang Shiffin. ${ }^{2}$ Disamping juga berbagai aliran lainnya seperti Asy'ariyah, Jabariyah, Qodariah, Murji'ah yang muncul atas reaksi aliran pendahulunya.

Berbagai aliran teologi Islam klasik diawali dengan perdebatan tentang Dzat Tuhan, Sifat Tuhan, kedudukan Tuhan, sehingga akibatnya diantara mereka saling menyalahkan, mengkafirkan bahkan menjadi ideologi negara yang dipatenkan. Fenomena kekerasan umat Islam yang disebabkan karena fanatisme terhadap ideologi masing-masing mengakibatkan kemunduran umat Islam dari berbagai bidang. Teologi Islam klasik telah memasung lama pemikiran umat Islam dalam situasi dan ruang waktu yang berbeda, sehingga mengakibatkan teologi Islam klasik kering dari makna dan tidak mampu berdealektika dengan realitas kehidupan. Terlebih di era kontemporer ini berbagai masalahan problematika muncul kepermukaan dunia seperti Hak Asasi Manusia (HAM), Gender, Liberalisme, Demokrasi, kesenjangan sosial, kekerasan dan lain sebagainya. ${ }^{3}$

Kondisi teologi Islam klasik di atas memunculkan berbagai tokoh pembaharu dengan konsepnya masing-masing seperti Al-Afgani, Arkoun, Muhammad Abduh, Muhammad Iqbal, Fazlurrahmann dan lainnya. Hasan Hanafi merupakan salah satu tokoh pembaharuan yang muncul untuk merumuskan kembali ajaran teologi Islam klasik sebagai dogma agama yang cenderung melangit (teosentris) menuju bumi (antroposentris) agar umat Islam peka

1 Achmad Faisol Haq, PEMIKIRAN TEOLOGI TEOSENTRIS MENUJU ANTROPOSENTRIS HASAN HANAFI, Spiritualis, Vol. 6 No. 2 Thn. 2020, hlm. 159-190.

${ }^{2}$ Haris Riadi, KENISCAYAAN REVOLUSI ISLAM (Menggagas Ulang Doktrin Teologi Revolusi Islam Hasan Hanafi), Jurnal Pemikiran Islam, Vol. 37 No. 2 Thn. 2012 hlm. 134-153.

3 Tauhedi As'ad, KRITIK PARADIGMA TEOLOGI ISLAM KLASIK: Membangun Hermeneutika Pembebasan Menurut Hasan Hanafi, al-'Adâlah,Vo. 16 No. 1 Thn. 2013, hlm. 281-296. 
dan mampu menyelesaikan berbagai permasalahan di era kontemporer ini, sehingga umat Islam tidak jauh tertinggal dari peradaban Barat. ${ }^{4}$

Terlebih revolisi industri Era 4.0 (for point zero) kemajuan dalam bidang indsutri mengalami perkembangan yang pesat sekaligus sebagai simbol lahirnya revolusi industri generasi keempat. Indsutri ini memadukan produk yang dihasilkan secara otomatis yang didukung oleh fasilitas yang berbasis internet. Definis sederhana yang dapat kita berikan untuk menggambarkan revolusi industri 4.0 yaitu kemajuan teknologi informasi dan komunikasi (TIK) berbasis internet yang begitu cepat dan dapat menunjangan kehidupan manusia dalam berbagai sekotr. ${ }^{5}$ Era revolusi industri 4.0 memaksa manusia untuk befikir keras agar mampu hidup dan mengembangkan kreatifitasnya sesua tuntutan zaman, karena jika tidak maka ia akan tenggelam oleh zaman itu sendiri.

Maka oleh karena itu, manusia harus mengambil peran serta menunjukkan eksistensinya dirinya untuk mengahdapi era indusri 4.0 ini, sehingga ia mampu hidup sejalan dengan perkembangan zaman. Tulisan ini akan mencoba untuk melihat bagaimana pemikiran teologi Islam Hasan Hanafi yang muncul atas respon pemikiran kalam klasik terlebih ditengah berbagai kompleksitas masalah yang dihadapi umat Islam saat ini. Kendatipun konsep teologi Hasan Hanafi lahir atas respon ilmu alam klasik, tetapi gagasannya memliki relevansi dengan kontkes kekinian, khususnya era revolusi industri 4.0.

\section{Metode Penelitian}

Tulisan ini termasuk dalam kategori jenis penelitian kepustakaan (liberary reseach), yaitu penelitian yang berusaha mengumpulkan data dengan melakukan penelaahan terhadap buku, literatur, catatan, serta berbagai laporan yang berkaitan dengan masalah yang ingin dipecahkan. ${ }^{6}$ Secara garis besar penelitian kepustakaan dibagi menjadi tiga bagian yaitu bidang kewahyuan, bidang pemikiran, dan yang terakhir bidang sejarah. ${ }^{7}$ Adapun ciri-ciri utama dari penelitian kepustakaan diantaranya pertama, peneliti berhadapan langsung dengan teks ataupun data angka, bukan dengan kelapangan, atau saksi mata, maupun bendabenda lainnya. Kedua, data bersifat siap pakai (readymade), artinya bahwa peneliti tidak akan turun kemana-mana, kecuali hanya berhadapan langsung dengan sumber yang telah tersedia di perpustakaan. Ketiga, umumnya data-data diperpustakaan merupakan data sekunder,

${ }^{4}$ Jarman Arroisi, Catatan atas Teologi Humanis Hasan Hanafi, Jurnal KALIMAH, Vol. 12 No. 2 Thn. 2014, hlm. 171-195.

${ }^{5}$ Bisyri Abdul Karim, Pendidikan Perguruan Tinggi Era 4.0 Dalam Pandemi Covid-19 (Refleksi Sosiologis), Education and Learning Journal, Vol. 1, No. 2, Juli 2020, pp. 102-112.

${ }^{6}$ Milya Sari dan Asmendri, Penelitian Kepustakaan (Library Research) dalam Penelitian Pendidikan IPA, NATURAL SCIENCE: Jurnal Penelitian Bidang IPA dan Pendidikan IPA, Vol. 6 No. 1 Thn. 2020, hlm 4153.

${ }^{7}$ Nursapia Harahap, Penelitian Kepustakaan, Jurnal Iqra', Vo. 8 No. 1 Thn. 2014, hlm. 68-73. 
artinya bahwa peneliti mendapatkan data dari tangan kedua, tidak bersumber dari lapangan langsung. Keempat, kondisi data di perpustakaan tidak dibatasi dengan ruang dan waktu. ${ }^{8}$

\section{Hasil dan Pembahasan}

\section{Potret Biografi dan Karir Intelektual Hasan Hanafi}

Hasan Hanafi lahir di Kairo Mesir pada tanggal 13 Februari tahun 1935, dan meninggal pada tanggal 21 Oktober 2021 saat usianya 86 tahun. Pada tahun 1948 Hanafi menamatkan pendidikannya pada sekolah dasar dan melanjutkan studinya di Madrasah Khalil Agha, Kairo pada tahun 1952. Di sekolah inilah Hanafi mulai berinteraksi dengan pikiran-pikiran dan gerakan Ikhwanul Muslimin, dan sewaktu kuliah di Universitas AlAzhar Kairo ia semakin aktif mengikuti gerakan ini sampai pada saat dibubarkan.

Pada tahun 1956 Hanafi berhasil menamatkan kuliah dan meraih gelar sarjana pada bidang filsafat di Universitas Cairo, setelah itu ia melanjutkan studi Doktorat di d'etat La Sorbonne Prancis, dan memperoleh gelar Doktor pada tahun 1966 dengan judul disertasi Esaai Sur La Mehode D'exegese (esaai tentang metode penafsiran) yang berjumlah 900 halaman dan berhasil menjadi karya tulis terbaik di Mesir pada tahun 1971. ${ }^{9}$ Sekembalinya dari Paris pada tahun 1966, Hassan Hanafi segera ditugaskan mengajar mata kuliah filsafat di Fakultas Sastra, Jurusan Filsafat Universitas Cairo Mesir. Ia juga sempat menjadi Profesor Tamu di Perancis (1969), Belgia (1980), Amerika Serikat (1971-1975), Kuwait (1979), Maroko (1982-1984), Jepang (1984-1985), Uni Emirat Arab (1985) dan menjadi konsultan akademik di Universitas PBB Tokyo (1985-1987).

Hassan Hanafi di samping seorang pemikir ke Islaman, ia juga penulis yang produktif. Banyak karya-karya tulisan yang dihasilkan dalam tiga bahasa, Arab, Inggris, dan Perancis yang dikuasainya. Di antara karya-karyanya adalah: Qadhaya Mu'asirah 1976-1977), Religius Dialogue and Revolution: Essays on Judaism, Christianity and Islam (1977), al-Din wa al-Tsaurah (1952 - 1981), Dirasat Islamiyah (1981), Dirasat Falsafiyah (1988), Min al-Aqidah ila al-Tsaurah: Muhawalih li I'adah Bina Ilmi ushul Al-Din (1988), Muqadimah fi ilmi alIstighrab (1991), dan lainlain. Selain menghasilkan karya-karya di atas, Hassan Hanafi juga menulis banyak artikel di beberapa jurnal ilmiah berbahasa Arab, mentahqiq teks-teks klasik Arab dan menterjemahkan beberapa buku tentang agama dan filsafat dalam bahasa Arab.

Di Prancis Hasan Hanafi mulai berfikir secara metodologis baik melalui proses perkuliahan maupun bacaan-bacaan Orientalis. Disamping itu Hanafi tertarik untuk menekuni pemikiran filsafat Idealisme Jerman terutama filsafat dialektika yang dipelopori

8 Mustika Zed, Metode Penelitian Kepustakaan, (Jakarta: Yayaysan Obor Indoensia, 2004), hlm. 4-5.

9 Mubaidi Sulaeman, Pemikiran Hermeneutika Al-Qur'an Hasan Hanafi dalam Studi Al-Qur'an di Indonesia, SALIMIYA: Jurnal Studi Ilmu Keagamaan Islam, Vol. 1, No. 2, Thn. 2020, hlm. 1-26. 
oleh Hegel dan Marx. Sehingga pada masa inilah kemudian Hanafi memulai proyek besarnya yaitu menciptakan metodologi dan teologi baru dalam Islam tentu dengan pendekatanpendekatan baru. Maka untuk mewujudkan misinya itu, Hanafi mengajukan desertasi sebagaimana yang telah disebutkan di atas. Judul ini sekaligus telah mewakili keinginannya untuk merumuskan Islam sebagai jalan metodologis secara kemprehensip baik dalam kehidupan personal dan sosial. ${ }^{10}$

\section{Sikap Hasan Hanafi Terhadap Kultural}

Dalam pandangannya, Hanafi melihat ada trend kemajuan dalam Islam dan fase kemunduran dalam dunia Barat. Hal yang senada juga pernah disampaikan oleh cendikiwawan Muslim Indonesia Ayuazumardi Azra dalam tulisannnya di majalah Tempo beberapa bulan yang lalu, ia mengungkapkan adanya trend kemunduran dalam dunia Barat, maka menurutnya kendatipun begitu, umat Islam tidak akan di untungkan jika berbagai problematika terutama konflik dalam internal umat Islam. Sementara itu bagi Hanafi, terhadap persoalan ini ia memiliki pandangan yang berbeda dengan kelompok konservatif seperti Sayyid Muhammad Qutub yang cenderung tertutup terhadap pradaban Barat dan menyerukan untuk melakukan pemurnian terhadap ajaran agama Islam yakni Al-Qur'an dan Hadis. Menyikapi trend kemajuan dalam dunia Islam, Hanafi memiliki tiga sikap kultural yaitu:

Pertama, sikap kita terhadap tradisi klasik. Kembali kepada kehidupan klasik sangat penting, karena kita merupakan masyarakat tradisional yang memiliki kesadaran nasional yang tumbuh dan lahir atas keterbukaan kita terhadap orang-orang yang hidup terlebih dahulu (qudama'). Orang-orang terdahulu selalu merefresentasikan otoritas mereka melalui kesadarannya. Maka oleh karena itu, persepsi dan tujuan kita terhadap dunia ini harus berangkat dari tradisi sehingga antara kita dan tradisi tidak dapat didistingsikan. Bahkan kritik yang kita lakukan terhadap tradisi untuk berdiri di era modern ini belum mampu memberikan dampak yang signifikan. ${ }^{11}$

Kedua, sikap kita terhadap tradisi Barat. Menurut Hanafi Barat harus diletakkan atau di lokalisasi pada batasan-batasan alamiahnya, serta menepis mitos-mitos yang mendewakan atau menjadikan Barat sebagai pusat pradaban. Sebagaimana paradigma kemajuan bangsabangsa lain. Walaupun harus diakui bahwa umat Islam jauh tertinggal jika berkaca pada kemajuan Barat, kendatipun begitu umat Islam masih mampu bertahan dengan standarnya sendiri. Imperealisme kebudayaan Barat jauh lebih berbahaya dengan bidang lainya seperti ekonomi, politik dan lainnya. Imperealisme yang dilakukan oleh Barat mencoba untuk menyerang umat Islam dari dalam (internal) kebudayaannya, sehingga Islam jauh atau tercabut dari akar kebudyaannya sendiri. Oleh karena itu, untuk membendung atau

${ }^{10}$ Achmad Faisol Haq, PEMIKIRAN TEOLOGI TEOSENTRIS MENUJU ANTROPOSENTRIS HASAN HANAFI...,hlm. 159-190.

${ }^{11}$ Hasan Hanafi, STUDI FILSAFTA 1: Pembacaan Atas Tradisi Islam Kontemporer, terj. Miftah Faqih, (Yogyakarta: PT LkiS Printing Cemerlang, 2015), hlm. 5. 
mengatasi masalah yang dihadapi oleh umat Islam, Hanafi mengusulkan satu konsep untuk menandingi Orientalisme Barat yaitu apa yang disebut dengan istilah Oksidentalisme. ${ }^{12}$ Bagi Hanafi kajian terhadap Barat mesti telah mulai diwujudkan, karena Orientalisme telah mengalami kematian, maka alternatif balik proses transformasi sejarah bisa ditemukan melalui Oksidentalisme. ${ }^{13}$

Ketiga, sikap terhadap realitas terkini. Ketajaman analisa dan pemahaman terhadap realitas kekinian, mengantarkan pada keberhasilan dalam berbagai gerakan sosial politik, maupun gerakan pradaban dan kebudayaan. Menurut Hasan Hanafi realitas adalah hal-hal yang kita hadapi saat ini yaitu masyarakat, ekonomi, kebudayaan, khazanah Islam dan realitas tantangan Barat. Realitas yang ada saat ini mengantarkan Kiri Islam (al-Yassir alIslamiyyat) untuk menemukan dan menguraikan permasalahan-permasalahan mendasar yang terjadi pada abad ini, seperti Imperialisme, Zionisme, Kolonialime, dan Kapitalisme yang datang dari luar. Sementara berbagai permasalahan lainnya yang datang dari umat Islam sendiri seperti kemiskinan, kekerasan, ketertindasan, dan keterbelakangan. ${ }^{14}$ Mengatasi Imperealisme dengan cara membongkar model-model baru dari gerakan ini seperti rasisme Barat, dan Salibisme historis yang terselubung. Kemudian berupaya melawan Zionisme dengan menolak akidah penguasaannya terhadap umat Islam. Sedangkan terhadap Kapitalisme baik itu global dan lokal, dengan menuntut orang-orang kaya untuk memberikan hartanya kepada orang miskin yang menjadi haknya, serta memanbangun masyarakat Islam yang berdasarkan atas persamaan dan keadilan sosial. ${ }^{15}$

\section{Rekonstruksi Pemikiran Teologi Hasan Hanafi dan Relevansinya dengan Revolusi Industri 4.0}

Revolusi indisutry 4.0 memiliki hubungan yang erat dengan manusia, artinya bahwa ketika manusia itu memiliki kompetensi yang baik, maka secara otomatis revolusi industry 4.0 yang kita cita-citakan akan tercapai, maka generasi muda dan khususnya Islam harus mempersipkan diri dan menunjukkan eksistensinya dalam mengarungi era revolusi industri 4.0 ini. Tuntutan untuk menunjukkan eksistensi dan mengambil peran dalam berbagai bidang kehidupan pada dasarnya merupakan ajaran islam sebagaimana makna kata Wujud (ada) dalam pandangan Hasan Hanafi bahwa wujud berarti tuntutan kepada manusia untuk

12 Gagasan Hanafi tentang Oksidentalisme pada dasarnya untuk mengakhiri mitos pradaban Barat. Hal ini penting untuk dilakukan untuk membangun diskursus yang kritis terhadap segala bentuk kemajuan pradaban dan kebudyaan yang berasal dari Barat. Lebih jauh lihat Ahmad Efendi Hadirois \& Suryo Ediyono, PEMIKIRAN HASSAN HANAFI TENTANG KRITIK TRADISI ISLAM (ANALISIS HERMENEUTIKA), Jurnal CMES, Vol. VIII, No. 2, Thn. 2015, hlm. 119-129. Lihat juga Abdurrohman Kasdi \& Umma Farida, OKSIDENTALISME SEBAGAI PILAR PEMBAHARUAN (Telaah terhadap Pemikiran Hassan Hanafi), Fikrah, Vol. I, No. 2, Thn. 2013, hlm. 231-252.

${ }^{13}$ H. Ahmad Munir, Hasan Hanafi: Kiri Islam dan Proyek Atturats Wa Al Tajdid...,hlm. 251-159. Diakses pada tanggal 13 November 2021 pukul 02 WIB.

${ }^{14}$ Hassan Hanafi, al-Yasar al-Islami, dalam al-Din wa al-Tsaurah, (Kaoro: Maktabah Madlubi, 1981), hlm. 48-52.

15 Kazuo Shimogaki, Kiri Islam antara Modernisme dan Postmodernisme: Telaah kritis Pemikiran Hasan Hanafi, (Yogyakarta: LkiS, 1996), hlm. 48. 
menujukkan eksistensinya di atas dunia ini dengan berprilaku positif, selain itu ia menginginkan agar wujud mengambil peran dalam berbagai dimensi kehidupan manusia. Berprilaku yang positif dalam agama telah jelas disebutkan dalilnya dalam Al-Qur'an dan hadis yaitu "sebaik-baik manusia adalah yang bermanfaat bagi orang lain" dengan begitu menunjukkan eksistensi dapat dilakukan dengan saling menolong, gotong royong, serta peduli terhadap orang lain, serta mengembangkan berbagai kemampuan yang dimiliki oleh masing-maisng individu agar ia tetap eksis di era revolusi inidustri 4.0 ini. ${ }^{16}$

Selain itu, kesiapan sumber daya manusia merupakan persyaratan mutlak yang harus disipakan dalam menghadapi era 4.0. Manusia yang handal, responsif, adaptif, serta memiliki pengetahuan luas adalah sebuah keharusan untuk menghadapi era revolusi industri 4.0 ini. ${ }^{17}$ Maka tentu untuk membangun ini dunia pendidikan memiliki peran penting untuk menciptakan manusia yang mengarah pada kebutuhan revolusi industri 4.0. Setidaknya tiga oreintasi pendidikan untuk mempersipakan revolusi industri 4.0 yaitu karakter, pengetahuan, dan soft skill. ${ }^{18}$ Dalam konsep teologi yang digagas oleh Hasan Hanafi, tuntutan untuk mengembangkan kemampuan, tentu dalam hal ini pengetahuan merupakan makna dari kata Qidham (Dahulu). Bagi Hasan Hanafi, selain manusia harus menunjukkan eksistensinya, maka ia juga harus memiliki pengetahuan disamping juga pengalaman yang luas pengetahuannya Qidam adalah modal pengalaman dan pengetahuan kesejarahan untuk digunakan dalam melihat realitas dan masa depan, sehingga bisa menghindarkan diri dari kesalahan taqlid, kesesatan dan kesalahan berifikir. Melihat kesejarahan umat Islam, adalah penting dilakukan. Karena umat Islam pernah menjadi pusat peradaban, pengetahuan dan kebudayaan dunia. Maka tidak heran jika salah satu ungkapan para ulama yang mengatakan "setelah manusia menunjukkan eksistensinya dalam kehidupan, selanjutnya manusia melakukan Qidham", hal ini sebagai modal pengalaman dan pengetahuan kesejarahan yang duganakan untuk membaca realitas dan masa depan, sehingga dengan begitu manusia tidak jatuh ke dalam lubang kesesatan, taqlid, dan kesalahan yang sama. ${ }^{19}$

Selain mengembangkan ilmu pengetahuan, secara fitrah manusia terlahir dengan kemampuan yang berbeda-beda yang dianugrahkan oleh Allah SWT. Oleh karena itu, potensi yang berbdeda-beda menjadi modal untuk bersaing, berdiri sendiri, dan tidak berpangku tangan dengan kebudayaan dan bangsa lain, sehingga akan tercipta manusia-manusia yang unggul dan produktif dalam berbagai bidang. ${ }^{20}$ Pandangan di atas sama dengan makna kata Mukhalafatu Li Al-Hawadist (Berbeda Dengan Yang Lain) dan Qiyam Binafsihi (Berdiri Sendiri) dalam konsep teologi yang Hasan Hanafi. Menurutnya Kedua sifat ini merupakan tuntutan

${ }^{16}$ Ahmad Zaenuddin, Dimensi Tauhid: Konstruki Relasional Jaringan Islam perspektif Hasan Hanafi, MIYAH: Jurnal Studi Islam Vol. 13 No. 01 Thn. 2017, hlm. 58-81.

${ }^{17}$ Bisyri Abdul Karim, Pendidikan Perguruan Tinggi Era 4.0 Dalam Pandemi Covid-19 (Refleksi Sosiologis)..., hlm. 102-112.

${ }_{18}$ Meti Hendayani, Problematika Pengembangan Karakter Peserta Didikdi Era 4.0, Jurnal Penelitian Pendidikan Islam, Vol. 7, No. 2, 2019 hlm. 183-194.

${ }^{19}$ Hanafi, LDORJ \$JDPD GDQ 5HYRORVL, (Jakarta, Pustaka Firdaus, 1991), hlm. 1.

${ }^{20}$ Meti Hendayani, Problematika Pengembangan Karakter Peserta Didikdi Era 4.0.., hlm. 183-194. 


\section{TEOLOGI HASAN HANAFI DAN RELEVANSINYA DENGAN REVOLUSI INDUSTRI 4.0 - Muhammad Yuslih}

kepada manusia untuk menunjukkan eksistensinya dan melepaskan diri dari ketergantungan dengan budaya dan pradaban orang lain, dengan bahasa yang lain tuntutan untuk berdiri sendiri. Secara alami, Allah SWT telah membekali manusia dengan sifat dan kemampuan yang berbeda-beda, sehingga hal ini dapat menjadi modal untuk menjadi berbeda dan berkualitas dengan yang lain.

Tentu hal ini bukan berati buruk, tetapi dengan keunggulan dan kapasitas yang berbeda-beda ini dapat menjadi pelengkap atau penyempuna dari kekurangan yang lain. Sementara Qiyam Binafsihi (berdiri sendiri) dijadikan sebagai pijakan untuk dan gerakan yang terencana yang dilakukan secara sadar untuk mencapai tujuan akhir. Pada akhirnya menurut Hanafi konsep ini diajukan dengan tujuan untuk membendung budaya dan pradaban yang menggroti kebudayaan umat Islam, dan juga untuk memunculkan kemandirian dikalangan umat Islam. Proses qiyam binafsihi tentu memerlukan perencanaan yang matang dan penuh kesadaran. Dalam aspek pemikiran, umat Islam dituntut kritis serta larangan untuk bersikap taqlid buta terhadap setiap bentuk pemikiran agar, bisa dapat menghasilkan pengetahuan yang komprehensif dan bisa membuat karya tanpa terus-menerus mengikuti pemikiran orang lain. ${ }^{21}$

Kemudian disadari atau tidak hadirnya revolusi industri 4.0 telah mempengaruhi kehidupuan sosial masyarakat. Kita harus mengakui bahwa saat ini manusia lebih banyak menghabiskan waktu maupun hidupnya dalam ruang-ruang yang dikenal dengan istilah siber (cyberspace). Sehingga akibatnya, kehidupan dalam nyata, begitu cepat untuk menyebar dalam hitungan waktu. Maka oleh karena itu, kita dituntut untuk lebih arif dalam menyampaikan isi pikiran dan jari mengontrol jari untuk tidak mengetik kata-kata yang tidak baik dalam ruang siber, agar terhindar dari hal-hal yang dapat merusak nama baik, ucapanucapan yang bermuatan kebencian, menyampaikan berita bohong (hoax), sehingga dengan begitu kita akan terhindar dari manusia-manusia cepat rusak dalam dengan kehadiran dunia siber. 22

Tuntutan untuk mengindara hal-hal yang dapat menyebabkan kerusakan merupakan makna dari kata Baqa' (kekal atau abadi) dalam konsep teologi Hasan Hanafi. Menurutnya baqa berarti kekal, pengalaman manusia yang muncul dari lawan sifat fana berarti tuntutan pada manusia utnk membuat dirinya tidak cepat rusak dan fana, yang itu bisa dilakukan dengan cara memperbanyak melakukan hal-hal yang konstruktif; dalam perbuatan maupun pemikiran, dan menjauhi tindakan-tindakan yang bisa mempercepat kerusakan di Bumi. Jelasnya, baqa adalah ajaran pada manusia untuk menjaga senantiasa kelestarian lingkungan dan alam, juga ajaran manusia mampu meninggalkan karya-karya besar bersifat monumental. Menjaga kelestarian alam merupakan salah satu tugas manusia di muka bumi

21 Manijo, MENGKONSTRUK AKHLAK KEMANUSIAAN DENGAN TEOLOGI KEPRIBADIAN HASAN HANAFI (Perspektif Teologi Antroposentris), Fikrah, Vol. I No. 2 Thn. 2013, hlm. 413-448.

22 Sri Ayu Astuti, Dampak Revolusi Industri 4.0 Dan Kemanfaatan Teknologi Media Digital Terhadap Perilaku Buruk Masyarakat Siber, Proceeding of Community Development, Volume 2 (2018): 483-494. 
sebagai wakil Tuhan (khalifatullah). Maka dari itu tidak dibenarkan perbuatan merusak, eksploitasi, destruktif dan lain-lain terhadap alam. Begitupun dengan hubungannya kepada manusia lain. Manusia dituntut untuk meninggalkan karya-karya yang monumental yang bisa membuat namanya tetap abadi. ${ }^{23}$

Kemudian dampak yang paling nyata hadirnya revolusi industri 4.0 ialah kehidupan ditengah-tengah masyarakat mengelami kesenjangan yang jauh. Artinya bahwa bagi masyarakat yang memiliki pendidikan tinggi akan semakin bergerak maju dengan mengikuti perkembangan zaman, tetapi tidak dengan masyarakat yang memiliki pendidikan rendah, ia akan tenggelam seiring dengan perkembangan zaman. Maka oleh karena itu, dibutuhkan persatuan dan kekompakkan untuk mengahadapi ini dalam kehidupan masyarakat. Persatuan dan kesatuan memiliki kesamaan dalam konsep teologi dalam pemikiran Hasan Hanafi yaitu dalam kata Wahdaniyyah (Keesaan).

Menurtunya Keeasaan Tuhan dalam pandangan Hasan Hanafi bukan merujuk pada makna penyekutuan Tuhan (syirik) sebagai pemahaman Trinitas dan Politeisme. Tetapi Hanafi membawa makna Keesaan Tuhan ke dalam ruang-ruang realitas atau kondisi sosial manusia. Wahdaniyyah adalah bentuk eksprimentasi manusia tentang kesatuan, baik itu kesatuan kelas, kesatuan nasib, kesatuan tanah air, kesatuan kebudayaan, dan kesatuan kemanusiaan. Lebih jauh Hasan Hanafi menjelaskan bahwa Wahdaniyyah adalah tuntutan kepada manusia untuk tidak melakukan praktek-praktek diskriminasi, eksploitasi tanpa batas, intimidasi kepada manusia lain. Wahdaniyyah merupakan ajaran tentang kesatuan manusia, kesetaraan manusia, keadilan umum dan lain-lain. Tidak ada yang membedakan antara manusia yang satu dengan manusia yang lain kecuali ketaqwaannya. Manusia dituntut untuk melakukan kasih sayang, baik kepada yang seagama maupun yang berbeda

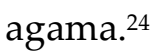

\section{Kesimpulan}

Teologi dan prilaku dua hal yang tidak bisa dipisahkan dari seseorang, hal ini menunjukkan bahwa apa yang menjadi keyakinan seseorang akan menjadi sikapnya dalam kehidupan sehari-hari. Hasan Hanafi merupakan salah satu teolog kontemporer yang perlu dibaca kembali gagasan teologinya, karena konsep teologi yang dibangunnya lahir atas problematika saat ini. Selain itu konsep teologi yang digagasnya dalam pembacaan penulis memiliki relevansi dengan revolusi industri 4.0. Revolusi industri 4.0 menuntut manusia untuk mengambil peran dan menunjukkan eksistensinya, kemudian mempersiapkan sumber daya manusia yang handal dan responsif terhadap segala bentuk perkembangan zaman,

${ }^{23}$ Nunu Burhanudin, Ilmu Kalam Dari Tauhid Menuju Keadilan Sosial, (Jakarta: PRENADAMEDIA GROUP, 2016), hlm. 165.

24 Zainuddin, PEMBELA GOLONGAN ISLAM MINORITAS (Pendekatan Kiri Islam Hasan Hanafi), Jurnal Qolamuna, Vol. 1 No. 1 Thn. 2015, hlm. 41-60. 
memiliki pengetahuan yang luas. Selain itu, manusia harus mampu menghindarkan diri dari segala bentuk perbuatan yang dapat membuat dirinya untuk rusak dan merugikannya, serta memperkuat ikatan persaudaraan sesama manusia, karena revolusi industri 4.0 selain mendatangkan dampak yang sangat positif, juga dampak yang buruk. Tuntutan di era revolusi industri memiliki kesamaan dengan konsep teologi Hasan Hanafi diantaranya Wujud (ada) merupakan untutan kepada manusia untuk eksistensinya di atas dunia ini, kemudian Qidam (dahulu) bermakna modal pengetahuan kesejarahan untuk melihat realitas dan masa depan, serta baqa' (kekal atau abadi), tuntutan kepada manusia agar tidak cepat rusak dan berbuat yang dapat merusak keseimbangan alam dan manusia serta bertindak positif, konstruktif, dan progressif, baik dalam perbuatan maupun pemikiran, Mukhalafatu li alhawadist (berbeda dengan yang lain) dan Qiyam Binafsihi (berdiri sendiri)Tuntutan untuk menunjukkan eksistensi diri dan tidak bergantung atau berpangku tangan pada orang lain, serta meninggalkan sifat taklid pada budaya orang lain. Dan yang terakhir Wahdaniyyah (kesatuan) yaitu perintah untuk tidak melakukan praktek-praktek diskriminasi, eksploitasi tanpa batas, intimidasi kepada manusia lain. Wahdaniyyah (kesatuan) merupakan ajaran tentang kesatuan manusia, kesetaraan manusia, keadilan umum dan lain-lain.

\section{Daftar Pustaka}

Astuti Ayu Sri. Dampak Revolusi Industri 4.0 Dan Kemanfaatan Teknologi Media Digital Terhadap Perilaku Buruk Masyarakat Siber, Proceeding of Community Development, Volume 2, 2018.

As'ad Tauhedi. KRITIK PARADIGMA TEOLOGI ISLAM KLASIK: Membangun Hermeneutika Pembebasan Menurut Hasan Hanafi, al-'Adâlah. Vo. 16 No. 1, 2013.

Arroisi Jarman. Catatan atas Teologi Humanis Hasan Hanafi. Jurnal KALIMAH, Vol. 12 No. 2, 2014

Burhanudin Nunu. Ilmu Kalam Dari Tauhid Menuju Keadilan Sosial. Jakarta: PRENADAMEDIA GROUP, 2016.

Hendayani Meti. Problematika Pengembangan Karakter Peserta Didikdi Era 4.0, Jurnal Penelitian Pendidikan Islam, Vol. 7 No. 2, 2019.

Haq Faisol Ahmad. PEMIKIRAN TEOLOGI TEOSENTRIS MENUJU ANTROPOSENTRIS HASAN HANAFI. Spiritualis, Vol. 6 No. 2, 2020.

Haris Riadi Haris. KENISCAYAAN REVOLUSI ISLAM (Menggagas Ulang Doktrin Teologi Revolusi Islam Hasan Hanafi). Jurnal Pemikiran Islam, Vol. 37 No. 2, 2012. 
Hanafi Hasan. STUDI FILSAFTA 1: Pembacaan Atas Tradisi Islam Kontemporer, terj. Miftah Faqih. Yogyakarta: PT LkiS Printing Cemerlang, 2015.

Hadirois Efendi Ahmad \& Ediyono Suryo. PEMIKIRAN HASSAN HANAFI TENTANG KRITIK TRADISI ISLAM (ANALISIS HERMENEUTIKA). Jurnal CMES. Vol. VIII No. 2, 2015.

Hakim Lukman. KONSTRUKSI TEOLOGI REVOLUSIONER HASSAN HANAFI. SUBSTANTIA. Vol. 12 No. 1, 2010.

Hanafi Hasan. Al-Yasar Al-Islami, dalam al-Din wa al-Tsaurah. Kairo: Maktabah Madlubi, 1981.

Kasdi Abdurrohman \& Farida Umma. OKSIDENTALISME SEBAGAI PILAR PEMBAHARUAN (Telaah terhadap Pemikiran Hassan Hanafi). Fikrah. Vol. I, No. 2, 2013.

Karim Abdul Bisyari. Pendidikan Perguruan Tinggi Era 4.0 Dalam Pandemi Covid-19 (Refleksi Sosiologis), Education and Learning Journal, Vol. 1 No. 2, 2020.

Manijo. MENGKONSTRUK AKHLAK KEMANUSIAAN DENGAN TEOLOGI KEPRIBADIAN HASAN HANAFI (Perspektif Teologi Antroposentris). Fikrah. Vol. I No. 2, 2013.

Munir Ahmad H. Hasan Hanafi: Kiri Islam dan Proyek Atturats Wa Al Tajdid. Diakses pada tanggal 13 November 2021 pukul 02 WIB.

Nursapia Harahap Nursapia. Penelitian Kepustakaan. Jurnal Iqra', Vo. 8 No. 1, 2014.

Shimogaki Kazuo. Kiri Islam antara Modernisme dan Postmodernisme: Telaah kritis Pemikiran Hasan Hanafi. Yogyakarta: LkiS, 1999.

Sari Milya, dan Asmendri. Penelitian Kepustakaan (Library Research) dalam Penelitian Pendidikan IPA. NATURAL SCIENCE: Jurnal Penelitian Bidang IPA dan Pendidikan IPA. Vol. 6 No. 1, 2020.

Sulaeman Mubadi. Pemikiran Hermeneutika Al-Qur'an Hasan Hanafi dalam Studi AlQur'an di Indonesia. SALIMIYA: Jurnal Studi Ilmu Keagamaan Islam. Vol. 1, No. 2, 2020. 
Zaenuddin Ahmad. Dimensi Tauhid: konstruki relasional jaringan Islam perspektif Hasan Hanafi. MIYAH: Jurnal Studi Islam.Vol. 13 No. 01, 2017.

Zainuddin. PEMBELA GOLONGAN ISLAM MINORITAS (Pendekatan Kiri Islam Hasan Hanafi). Jurnal Qolamuna. Vol. 1 No. 1, 2015.

Zed Mustika. Metode Penelitian Kepustakaan. Jakarta: Yayaysan Obor Indoensia, 2004. 